Br Heart $\mathcal{f} 1987 ; 57: 393-6$

\title{
Correspondence
}

\section{Detection of coronary artery disease by thallium scintigraphy in patients with valvar heart disease}

Sir,

The results reported by Huikuri et al (1986;56:146-51) who used thallium scintigraphy to detect coronary artery disease in patients with valvar disease do not accord with what we found in similar patients. We used thallium-201 scintigraphy to study a group of 21 patients with severe aortic valve disease (nine with aortic stenosis, five with aortic regurgitation, and seven with combined aortic stenosis and regurgitation) and angiographically normal coronary arteries and a control group of 21 young individuals free from heart disease. ${ }^{1}$ In the image obtained after stress testing 17 of the 21 patients with aortic valve disease had thallium uptake defects with partial or total redistribution. Findings were positive in only one of the controls. We concluded that so-called "ischaemic" patterns were common in patients with severe aortic valve disease and angiographically normal coronary arteries and that thallium scintigraphy had a low specificity $(19 \%)$ for the diagnosis of associated coronary artery disease. In a later study we found that in patients with severe aortic regurgitation and normal coronary arteries there was a significant correlation between these defects in thallium uptake and wall motion abnormalities detected by equilibrium gated radionuclide angiography. ${ }^{2}$

In contrast, Huikuri et al found that thallium scintigraphy had a sensitivity and specificity of about $90 \%$ in a series including 15 patients with mitral valve disease and 33 patients with aortic valve disease. We think that several factors may have contributed to this discrepancy:

(a) In our series higher heart rates were obtained (for similar ages) during stress testing. ${ }^{1}$ This could reflect a higher level of cardiac work, with a higher likelihood of disclosing perfusion defects (or "relative ischaemia") with a thallium scan.

(b) Aortic valve disease was more severe in our series $^{1}$ with presumably a greater left ventricular mass and a smaller coronary reserve. This could explain the higher rate of "false positive" findings on thallium scans. In the series reported by Huikuri $e t$ al the inclusion of 15 patients with mitral valve disease could also have improved their results.

(c) Although in both studies a semiquantitative method was used to evaluate the thallium scans, the method used by Huikuri et al is less subjective (interobserver agreement of $94 \%$ ) but probably not less sensitive or more specific than ours. ${ }^{1}$

(d) Huikuri et al regarded all scans showing hypoperfusion in any area except the apex as positive whether or not there was redistribution, whereas we regarded scans showing hypoperfusion after stress as positive only when there was partial or total redistribution in any area including the apical zone. Only three patients in our series (one with aortic stenosis, one with aortic regurgitation, and one with mixed stenosis and regurgitation) had post-stress defects limited to the apical zone with partial or total redistribution. If these three cases are excluded, however, as suggested by Pfisterer et al, ${ }^{3}$ the specificity would be increased only from $19 \%$ to $33 \%$-thus this cannot be the only reason for the different specificity values.

These factors may explain the different results obtained in both studies. The discrepancy shows that one should be cautious about claiming or denying that the thallium scan is useful for the detection of coronary disease associated with aortic valve disease. It also shows that results from a laboratory may not be comparable, particularly if different methods and interpretation criteria are used. We therefore agree with Huikuri et al that it is premature to state that thallium scintigraphy can replace coronary arteriography in the diagnosis of coronary artery disease in patients with valvar heart disease.

J Candell-Riera,

Servicio de Cardiología,

J Castell-Conesa,

D Ortega-Alcalde,

Servicio de Medicina Nuclear,

Ciudad Sanitaria "Vall d'Hebron",

Barcelona,

Spain.

\section{References}

1 Candell J, Ortega D, Castell J, et al. Gammagrafia miocárdica de esfuerzo y redistribución con talio-201 en pacientes con valvulopatía aórtica severa y coronarias 
angiográficamente sanas. Rev Esp Cardiol 1985; 38:332-7.

2 Castell-Conesa J, Candell-Riera J, Rius Davi A, Ortega-Alcalde D. Estudio isotópico de las alteraciones de la perfusión y contractilidad segmentaria de pacientes con valvulopatía aórtica severa y coronarias sanas [Abstract]. Rev Esp Med Nucl 1986;5 (suppl I):29.

3 Pfisterer M, Muller-Brand J, Brundler H, Cueni T. Prevalence and significance of reversible radionuclide ischemic perfusion defects in symptomatic aortic valve disease patients with or without concomitant coronary disease. Am Heart $\mathcal{F}$ 1982;103:92-6.

This letter was shown to Dr Huikuri, who replies as follows:

Sir,

We are grateful to Dr Candell-Riera and his colleagues for commenting on their experience of thallium imaging in aortic valve disease. We are somewhat surprised by their reports of low specificity.

We do not know the details of how the images were assessed in their study. It is well known that the interpretation of thallium images is subjective and it is often difficult to define abnormal thallium perfusion. Misinterpretation of irregular thallium uptake in the apical region, which was commonly seen in our study (especially in severe aortic regurgitation) and has also been described by Pfisterer et $a l,{ }^{1}$ is a possible source of false positives. These defects are not strictly limited to the apex, but extend partly to the inferior region. These inferoapical defects should not be regarded as representing a coronary artery disease. The peak heart rate achieved during exercise was higher in patients studied by Candell-Riera et al. It is possible that subendocardial ischaemia occurring during maximal exercise in critical aortic valve disease can reduce the thallium uptake of the myocardial cells and result in thallium defects despite normal coronary arteries. It has been our policy not to continue exercise until severe symptoms develop because of the possibfe hazards of maximal exercise testing in patients with severe aortic stenosis. This factor may explain the lower number of false positive scans in our study $\overline{0}$

We have continued our thallium studies in pa् tients with aortic stenosis by using dipyridamole is fusion as a stress test. ${ }^{2}$ In this pilot study we found thallium imaging to be $86 \%$ sensitive and $87 \%$ specific in detecting angiographically significant cor ronary artery disease. Because of these results we now prefer dipyridamole stress testing to dynamif exercise testing in patients with critical aortic sten $Q^{2}$ sis. These patients often have a poor exercise tole ance which limits the usefulness of exercise testirg in conjunction with thallium imaging. Coronary vasodilation with dipyridamole does not result in my f $^{2}$ cardial ischaemia in a hypertrophied left ventricte without coronary artery disease and may also im prove the specificity. We certainly agree with Candell-Riera et al that none of the non-invasive methods can yet replace coronary angiography im patients with valvar disease and suspected concom $\overrightarrow{\dot{p}}$ tant coronary artery disease. More studies are needed.

Heikki V Huikuri, Division of Cardiology, Department of Medicine, Oulu University Central Hospital, Oulu,

Finland.

\section{References}

1 Pfisterer M, Muller-Braud J, Brundler H, Cueni Prevalence and significance of reversible radiô. nuclide ischemic perfusion defects in symptomasc aortic valve disease patients with and without concomitant coronary disease. Am Heart J 198\%; 103:92-6.

2 Huikuri HV, Korhonen UR, Ikäheimo MJ, Heikkilä $\widehat{d}$, Takkunen JT. Detection of coronary artery disease by thallium imaging using a combined intravenots dipyridamole and handgrip exercise test in aortîte stenosis. Am $\mathcal{F}$ Cardiol (in press).

\section{The cause of rheumatic heart disease}

Sir,

Dr William L Proudfit's recent review entitled "John Hunter: on heart disease" is a most interesting and valuable contribution. In it he mentions the question of whether Edward Jenner or Dr David Pitcairn should rightfully be credited with having initially associated valvar heart disease with precedent rheumatic fever. He suggests that Pitcairn's claim rests upon a footnote in the second edition of
Dr Matthew Baillie's textbook published in 1797 , whereas Jenner was known to have spoken on the subject to the Gloucestershire Medical Society i⿱一⿻冂从丨 1789. ${ }^{2}$

There is, however, stronger evidence than this for Pitcairn's claim. On 3 April 1810 William Charle Wells read a paper entitled "On rheumatism of the heart" to the Society for the Improvement of medis cal and chirurgical Knowledge. ${ }^{3}$ Wells was 